\title{
German Studies in the USA: A History of Crises
}

Patricia Herminghouse (Rochester)

For most of the twentieth century, the story of German Studies in the United States can be written as a history of crises. The trajectory of developments that seemed to threaten the teaching of German language and culture can be traced from the anti-German sentiments of the World War I era through contemporary corporate models that view humanistic study in terms of market value. One exception to this story might have been the post-Sputnik Cold War era of the late 1950s, which witnessed the promulgation of the National Defense Education Act. Among the implications of that legislation for language programmes, including departments of German, was the challenge of providing more and better language training utilising the new technology of language laboratories and a host of innovative teaching methods, most of which nonetheless failed to increase language proficiency or to communicate cultural knowledge in meaningful ways. By the end of the 1960s, this government funding, which had also let to a bonanza of college teaching jobs in German, had all but dried up. To stem this loss of funding and jobs, many language departments saw in the multi-disciplinary "area studies" programmes that had been developed in response to presumed "American national and economic interests" a way to ally themselves with other disciplines that seemed to offer access to jobs in fields more promising than teaching German.

Responding to the crisis of these years, several colleagues and I drafted a proposal for just such a German Area Studies programme in German. At that time we observed that

[b]oth traditional scholarship and traditional ways of education are being challenged by a new generation of students who feel that conventional departmental programs do not recognize the heart of the problems with which our society is faced. Modern language programs [...] have emphasised a highly specialized training in the language and literature of a foreign culture, neglecting more or less 
social and political aspects [...]. The new generation of undergraduate students is drifting in the direction of general studies, especially towards interdisciplinary studies. They have lost faith in antiquarian or esoteric learning for the sake of learning. They are searching for an education which will help them understand the environment in which they are living.

The desire to develop a new approach to German Studies based on the model of area studies gained support in the 1970s in the wake of rebellions against curriculum requirements in general and the language requirement in particular. In crude terms, many of the new German area studies programmes represented attempts on the part of German departments to demonstrate "relevance" and thereby to salvage at least parts of their national language and literature offerings through the admixture of non-literary courses in more popular and practical fields. Nonetheless, such programmes often remained fundamentally conservative and traditional in outlook. With little reflection on what genuine interdisciplinarity might mean, these multidisciplinary programmes were content to function as collection-baskets for course offerings from various cognate departments. The "area" conceived by such area studies programmes could be described as a geographically bounded field where neighbouring disciplines were juxtaposed, but not necessarily integrated, into a model of " $x$ " courses from discipline " $a$ " and " $y$ " from discipline " $b$ " and no more than " $z$ " from discipline "c" (typically the German department). While this articulation of area studies revealed the dawning recognition that traditional German "Germanistik" was losing its appeal in a North American setting, the new "market basket" model of multi-disciplinarity meant that links between disciplines arose largely as a result of happenstance, that is, through the manner in which the student clientele chose course offerings in combinations that made sense to them. Despite pragmatic arguments on behalf of broad education and against the narrow specialisation of the traditional model of "Germanistik," the generalist brand of area studies, conceived as a centripetal model with Germany at its centre, struggled to maintain the interest and commitment of faculty from the far reaches of allegedly kindred disciplines. All too often in the 
case of the "market basket" approach, however, the centre did not hold: the mere juxtaposition of courses lacked the power of attraction, both for research-oriented faculty and for students in search of some coherence in their course of study.

Before anything was done to integrate the methods and materials of the various disciplines into a model of genuine interdisciplinarity, a new problem arose: a paradigm shift in the social sciences made participation in nationally-oriented enterprises much less interesting, especially for political scientists and economists. With prestige in these fields increasingly accruing to more theoretical work, language scholars were left feeling that they needed scholars in cognate disciplines more than these scholars needed them. In contrast to programmes in women's studies, Jewish studies, and African-American studies that were successfully responding to the ways their subjects had been marginalised and excluded in American society, the 1970s version of German area studies failed to provide compelling answers to the question of "relevance" that was looming large in the mind of students and the wider community. Unlike other regional and area programmes such as Soviet, East Asian, Near Eastern, or Latin American area studies, which were also a product of this era, German area studies did not appear vital to the political and economic imperatives of the "national interest," despite the emergence of the German Democratic Republic on the international scene.

By the mid 1980s, however, the decline of the North American commitment to "things German" had become a matter of concern to the Federal Republic of Germany, which, particularly through the German Academic Exchange Service, sought to revitalise the area studies paradigm. American academics were brought together to engage in intensive dialogue about a new type of programme, then called simply "German Studies," and now, increasingly, German Cultural Studies. As these efforts were undertaken, it became clear that efforts to remedy the situation would have to be guided intellectually and structurally by the needs of students, faculty, and institutions in our own North American context. 
This renewed attempt to position German Studies in the academic mainstream meant, among other things, raising more complex questions about how a field is constituted and legitimised and how a disciplinary identity is communicated to the outside world. "Germanistik," the term which described our discipline as a foreign off-shoot of the "real thing" in German universities, as well as that old locution "Landeskunde," which connoted a Germanophilic approach to people and places, had left unexamined most of the assumptions of our own culture as well as those, for that matter, of the "target" culture.

By the early nineties, the social, political, and geographical transformation of Germany and its situation in the European community, the tidy dichotomies of East/West, German/foreign as well as the old monolithic representations of German-ness that originated in nineteenth-century longings for nationhood were being challenged by explorations of cultural identity in terms of hybridity, intersections, and margins. Meanwhile, within the humanities themselves, that which had hitherto been excluded from a white, middle-class, heterosexual orientation to "culture" had begun to inform the various cultural studies approaches. Drawing on an international corpus of "theory," these approaches held out the promise of transcending the narrowly conceived "national" literary canon that RuthEllen Joeres has aptly referred to as a demonstration of "the aesthetic prowess of a country." The notion of a paradigmatic ethnic monoculture that underlay "Germanistik" was rapidly losing its credibility. Despite massive retrenchments, a new generation of scholars who were less oriented towards high culture but far more theoretically minded began to make their mark on the profession. Some of our brightest students as well as many younger colleagues have been shifting their intellectual energies out of the disciplinary isolation of "Germanistik" into interdisciplinary programmes and centres, such as film studies, post-colonial studies, gender studies, and gay, lesbian and queer studies (fields self-consciously located on the margins of the "national" discipline as it was traditionally

\footnotetext{
${ }^{1}$ Ruth-Ellen Boetcher Joeres: Respectability and Deviance: Nineteenth-Century German Women Writers and the Ambiguity of Representation. Chicago: University of Chicago Press $1998,51$.
} 
conceived). With the rise of cultural studies, the entire discourse of nation on which "Germanistik" had been predicated has lost much of its credibility and power of attraction. A lot of heat was generated by the apparent preference of cultural studies practitioners for less "monumental" subject matter, their insistence on the contingency of meaning rather than general maxims, and their preferred interrogations of "representation" rather than "reality."

Further impetus for change has come from shifts in disciplinary identifications within the larger context of the debates on theory, the structure of disciplines, and the construction of curricula. As a result of the now widely occurring move toward interdisciplinarity, the old-style "department" has begun to lose much of its former identity as a teaching and research unit, becoming instead a conglomerate or "Centre" (with a capital "C"!) that "includes a number of disciplines, sub-disciplines, or specialisations." 2 The effect on language departments can be disorienting, to say the least: competing demands for faculty contributions to such centres, the threat of having bread-and-butter "service" courses moved into language centres, the need to support staffing budgets with largeenrolment courses taught in English increasingly make it difficult to maintain the nucleus of national literature courses that had long been the core of traditional German department offerings.

Yet another development of the 1990s, promoted under the banner of "globalisation," urged us to prepare our students for a new era of instant and electronic communication, to enable them to operate in a global marketplace without borders and barriers to the movement of commerce, capital, and ideas. Slowly, we came to realise that globalisation and the corporatisation of the university that went with it contained, for better or worse, the potential to put into question much of our development as a separately constituted discipline area - especially on account of the presumed hegemony of Anglo-American culture and social values that accompanied it. This outlook is reflected in the increasing disinclination

\footnotetext{
2 Valters Nollendorfs: "Out of Germanistik: Thoughts on the Shape of Things to Come." Die Unterrichtspraxis 27 (1994): 5.
} 
of academic administrators to support region-centred programmes, unless they succeed in obtaining their own outside funding. Thus the good news that once seemed implicit in administrators' talk of "globalising the curriculum" has in most cases not been of genuine benefit to the study of languages and cultures. The "national interest," the rationale of older area studies programmes, seems to have been displaced in the "global economy" by pursuit of competitiveness, efficiency, applicability, and marketability. These changes are reproduced in the allocation of institutional resources: insistence on measurable outcomes, institutional returns on investments in academic programmes, "right-sizing," out-sourcing, and the reconfiguration of academic units. Market analyses of potential student "consumers" and competitors are now commonplace.

While one might assume that the need for cultural competence would go hand-in-hand with the globalisation of trade, technology, research, and culture, the decline of humanistic education has made the connection between educational goals and the forces of economic and political globalisation appear less certain. In the recent formulation of Peter Hohendahl, we are now confronted with a "neoliberal notion of the university as a specialized corporation that provides the market with applicable empirical knowledge and holders of advanced degrees who have been trained, in academic institutions that have taken on the form of businesses, to function in the world of business."3

There are also other obstacles to the kind of collaboration envisioned by the German Studies model. Institutional "bean-counting" of credit hours, majors, and minors frequently militates against the cooperation on which strong interdisciplinary programmes depend. This can result in the temptation to draw within departmental boundaries material that should otherwise be the province of adjacent disciplines. The academic reward system itself, increasingly based on a competitive model of autonomous production of knowledge documented in single-author publications and independently taught courses, can also work against interdisciplinary

\footnotetext{
${ }^{3}$ Peter Uwe Hohendahl: "Three Decades of Crisis: What is the Purpose of a $\mathrm{PhD}$ Program in Foreign Languages?" PMLA 115.5 (2000): 1229.
} 
cooperation and scholarly collaboration. The scholar who strays beyond departmental boundaries to obtain a grounding in cognate fields may be suspected of dilettantism or lack of focus and commitment to his/her disciplinary home. ${ }^{4}$ It was in this confusing context that the German Studies Association set out to revise a set of Guidelines for Curricular Organization at American Educational Institutions that it had previously disseminated in 1987 . We began by surveying our members in order to gain some concrete, first-hand information about trends and needs in the field. The responses (unpublished) indicated by a margin of more than three-to-one that their scholarly work had increasingly moved in German Studies directions. More than half these colleagues also indicated that degree-granting German Studies programmes had been established at their institutions. There may be a certain amount of "tilt" at work in these high reported levels of German Studies activity since, in fact, the respondents were already members of something called the "German Studies Association." Of concern was the fact that few respondents - less than ten per cent - thought of "German Studies" in terms of methodological approaches. Indeed only a minority (less than twenty per cent) of those respondents whose institutions had a German Studies programme reported courses that "explore[d] theoretical and methodological questions regarding what it means to do German Studies." Although theory has shaped assumptions that underpin our field, there is scant evidence that theory has found its way into the formal curriculum of most programmes. The task is admittedly complex because the issues are both definitional and epistemological, with theoretical assumptions that in most cases range far beyond the traditional purview of German departments.

The editors of the journal Monatshefte also reported on a survey of German Studies programmes in 1995. This - the third survey of German Studies programmes the journal has undertaken since the early 1980s also documented an impressive pattern of growth in the field: roughly one third of the programmes in existence in the mid-1990s were established in

\footnotetext{
${ }^{4}$ Another effect that bears mentioning here, at least in passing: the hardening of professional class lines that ever more rigidly separate a privileged academic elite from the academic underclass whose labours keep the enterprise going.
} 
the decade since Monatshefte had published its previous German Studies survey in 1986. Of the Monatshefte respondents, only slightly more than ten per cent of the 208 responding departments indicated that there were no German Studies courses at their institutions. ${ }^{5}$ For Germanists, the editors concluded, "the centre of gravity" was now to be found in German Studies. Whether the programmes were so labeled or not, about half the students enrolled in "German" were now taking German Studies in one way or another. ${ }^{6}$

The new GSA Guidelines for Curricula in German Studies at Universities and Colleges in North America, published in 1998, avoid being overly prescriptive about programme offerings. ${ }^{7}$ Nevertheless, five elements are emphasised as essential: proficiency in the language adequate to the purpose and level of study; at least one course in nineteenth- and twentieth-century German and/or European history; study or internship experience in a German-speaking country, where possible; a capstone integrative experience - either a research paper or seminar, or both; and respect for the standards and methods of related disciplines. A final position on the double identity lurking behind the name "German Studies" was not taken. Russell Berman has characterised these two identities as "großdeutsch" (the collaborative multi- or interdisciplinary approach to the study of Germany represented by the GSA itself, for example) and "kleindeutsch" (the programme of the single German department offering an extended purview of cultural texts beyond the canonically literary, often drawing on the methods and approaches of Anglo-American cultural studies). ${ }^{8}$ The Guidelines advocate a convergence of these two approaches and encourage German Studies scholars "to obtain further training in disciplines outside their own field, pursue

\footnotetext{
${ }^{5}$ To put the numbers reported in this section in perspective: out of 350 known US and Canadian departments offering German in 1994, 200 grant the bachelor's as the highest degree, 61 the $\mathrm{MA}$, and 66 the $\mathrm{PhD}$ (Nollendorfs 2). In light of on-going administrative reductions in programmes and faculty, current figures for "German" would be somewhat lower, although the trend towards "German Studies" continues.

6 "Special Survey: German Studies Programs and Courses." Monatshefte 87.3 (1995): 363

${ }^{7}$ These Guidelines can be found on the GSA website: www.g-s-a.org.

${ }^{8}$ Russell A. Berman: "Global Thinking, Local Teaching: Departments, Curricula, and Culture." ADFL Bulletin 26.1 (1994): 7-11.
} 
other possibilities for inter- and multidisciplinary scholarship and teaching, seek administrative arrangements that facilitate such work, and train their students in interdisciplinary methods" (8). ${ }^{9}$ Among the best ways to achieve these goals, of course, are practices such as teamteaching and collaborative research and publication. Unfortunately, these strategies often run into obstacles erected by the very administrators who talk of the need for "interdisciplinarity" in the first place.

The new Guidelines also emphasise that the training of German Studies scholars should provide a solid grounding in the methods and materials of the related discipline(s). As the French historian Lynn Hunt has pointed out:

Interdisciplinarity cannot live without the disciplines. Its promise of daring escape from confinement, heady transgression of expected conduct, and even the potential chastisement by those more orderly and predictable - depends on the certainty of disciplinary borders. You cannot cross boundaries if you don't know where they are $[\ldots]$ you have to know where the lines fall that divide history and art history, history and literature. ${ }^{10}$

In my work with the GSA committee that produced the new Guidelines it became evident that Germanists who identify with German Studies were often less insistent on language proficiency than either their colleagues in traditional language and literature programmes or those in social science disciplines. ${ }^{11}$ While more traditional Germanists worry

\footnotetext{
${ }^{9}$ In support of this goal, GSA has just entered into a collaborative arrangement with the Berlin Programme for Advanced German and European Studies, which provides dissertation-level and new $\mathrm{PhD}$ North American scholars the opportunity to develop their research for one year in a rigorously interdisciplinary setting. Information about the programme can be found on the GSA website, www.g-s-a.org.

${ }^{10}$ Lynn Hunt: "The Virtues of Disciplinarity." Eighteenth-Century Studies 28.1 (1994): 1.

${ }^{11}$ While the new Guidelines do, in fact, advocate higher levels of language preparation, they stop short of using the terminology of the "ACTFL Proficiency Guidelines" to specify appropriate competence, in part because many committee members felt that the terminology promised much more than the actual performance being described, especially for the college and university level: An "intermediate" speaker, for example, "can generally be understood by sympathetic interlocutors"; an "advanced" reader is "able to read somewhat longer prose of several paragraphs in length, particularly if presented with a clear underlying structure [...] in familiar sentence pat-
} 
about a diminution of their subject matter - particularly the ceding of turf to theory and cultural studies taught in English - not a few scholars in other disciplines, especially historians, expressed concerns about threats to the integrity of their discipline from the dilettantism of German literature specialists, who, rather than providing students the German language skills they need to do solid archival work, are drawn to the charged topics of German history and philosophy without any proper grounding in these disciplines.

Rethinking our mission in what is sometimes described as the "postnational" era, therefore, increasingly entails addressing not only the question of "German Studies," but the role of national languages and literatures in a transnational and trans-cultural world, where English is the lingua franca by default. In contrast to the early years of the German area studies movement in the 1970s, the crisis of disciplinary identity has become critical: the very survival, not merely the well-being, of many German programmes is now at stake. How do we make the case for humanistic education - and not just the Western canon - in the face of ever greater demands for pragmatic professional specialisation in the interest of competitiveness, efficiency, and marketability? Martha Nussbaum has described three essential abilities that liberal education must provide for citizenship in today's world:

First is the capacity for critical examination of oneself and one's own traditions [...]. Second is the ability to think of oneself [...] [as] a citizen of the world, rather than merely of some region or group $[\ldots]$. To attain this ability [...] students need to learn a great deal more than students in previous generations typically did about

terns." On the other hand, the formulations of the new "Five C" standards for foreign language learning in grades K-12 suggest the need for teacher preparation along the very lines envisioned by the new GSA Guidelines, (which, incidentally, have shifted their emphasis from what the precollege teacher must do and know to the sort of preparation and on-going support they need to receive from our programmes): "Communication: communicate in languages other than English; Cultures: gain knowledge and understanding of other cultures; Connections: connect with other disciplines and acquire information; Comparisons: develop insight into the nature of language and culture; Communities: participate in multilingual communities at home and around the world." 
the history and culture of non-Western people, and of ethnic and racial minorities within their own culture; about the achievements and experience of women; and about the variety of human sexuality.

Finally, there is the importance of that which she calls the "narrative imagination": the ability to understand what it might be like to experience life from a position other than one's own, the ability to become an intelligent reader of other life stories despite the many difficulties attached to intelligent reading of these life stories. This ability, she points out, is cultivated, above all, through course offerings in literature and the arts. ${ }^{12}$

There are, of course, Germanists (Alice Kuzniar, for example) who now argue that abandoning an insistence on language fluency as a foundation of German cultural studies is necessary "not just to save our jobs but, more importantly, to contribute to major debates in the arts and humanities." 13 In this view, surrendering use of the German language is the price that one has to pay for survival in the current environment, the way to gain an influx of students from other departments and entrée into campus-wide intellectual endeavours, such as film studies. Other colleagues, notably Claire Kramsch, insist that German Studies must be grounded in language study - not merely in terms of mastery of the vocabulary, grammar and pronunciation of the target language, but as "cultural fluency," which results from conscious reflection about the ways in which language structures cultural experience. ${ }^{14}$

Some encouraging progress is being made in addressing the mistakes that have led to the separation of language learning from the study of cultural material. The discourse analysis approach developed by Heidi

\footnotetext{
${ }^{12}$ Martha Nussbaum: Cultivating Humanity: A Classical Defense of Reform in Liberal Education. Cambridge, MA: Harvard UP 1997.

${ }^{13}$ Alice A. Kuzniar: "Cross-Gendered Cross-Cultural Studies and the German Program." The Future of Germanistik in the USA: Changing Our Prospects. Ed. John A. McCarthy and Katrin Schneider. Nashville: Vanderbilt UP 1996, 123.

${ }^{14}$ See Claire Kramsch: "Introduction: Making the Invisible Visible." Redefining the Boundaries of Language Study. Ed. Claire Kramsch. Boston: Heinle and Heinle 1995. See also: Claire Kramsch: Language and Culture: New York: Oxford UP 1998.
} 
Byrnes and her colleagues at Georgetown University, for example, aims to reconnect language study with the German [Cultural] Studies agenda. ${ }^{15}$ Another effective linking of language and content in the German curriculum is Stanford's highly integrated language-and-culture approach. ${ }^{16}$

We need more strategies such as these that highlight the cultivation of interpretative and analytic skills and evoke students' curiosity about intercultural perspectives. We need to demonstrate to students the intellectual and practical benefits of studying another language and acquiring the necessary skills and cultural competence to function in a culture that is not their own (which is not the same thing as "near-native fluency"). We also need more effective ways of explaining to colleagues, administrators, and the community why learning to become astute readers of the "texts" of another culture (as well as of one's own!) is an important aspect of humanistic education. Study of such broadly conceived "texts," including literary texts, leads to cultural competence when attention is paid not just to what texts "mean," but also to how meaning is culturally determined and encoded. Focused on the goal of cultural competence, the integrated study of language, literature, culture, and theory within a German Studies context stands on its own and is neither the pretext around which the German Studies agenda is constructed nor a lame substitute for courses that remain the proper province of other disciplines. Beyond concerns about discrediting ourselves with dilettantish forays into foreign disciplines, Germanists should also consider the danger of somewhat reckless abandonment of our own "cultural capital" in the uncertain environment of interdisciplinarity and globalisation. We are still learning to negotiate the tricky line between the alternatives of surrendering our own disciplinary specificity to generic cultural studies on the one hand and asserting the transcendent values of German language and literature on the other.

\footnotetext{
${ }^{15}$ See Heidi Byrnes and Susanne Kord: "Developing Literacy and Literary Competence: Challenges for Foreign Language Departments." SLA and the Literature Classroom: Fostering Dialogues. Ed. Virginia M. Scott. Boston: Heinle \& Heinle, 2002, 35-73.

${ }^{16}$ See Russell A. Berman and Elizabeth Bernhardt-Kamil: "From German 1 to German Studies 001: A Chronicle of Curricular Reform." Die Unterrichtspraxis 32 (1999): 22-31.
} 
How can we balance our conviction that the study of language and culture in our "national" departments must be preserved even as our intellectual energies increasingly gravitate toward interdisciplinary centres? Can we address the apparent contradiction between the call for interdisciplinary practice and the fact that most German departments continue to recruit faculty along the traditional lines of national canon and literary genre? This practice seems particularly odd in view of the fact that German programmes themselves have been abandoning the old fixation on periods and genres in favour of course offerings based on "problems" or topics that integrate components of German culture in new ways.

My own assessment is that we would be well advised to move away from the old one-size-fits-all approach of a curricular model that clings to a notion of wholeness and "coverage" that fits almost none of the programmes we know about anyhow. Rather, we should foster specific forms of collaboration among disciplines with particular affinities with one another. In addition to the interdisciplinarity of German Studies advocated in the new GSA Guidelines, a multicultural focus across several "national" disciplines may well contribute to breaking down the tendency to study areas of the world as isolated entities. Such a focus could promote understanding of competing economic, political, and cultural claims among nations as well as foster a new thinking across the imbricated relationships of the global and the local. There is practical work to be done in connecting the study of non-Western European cultures with the study of things German in these cultures. By developing a more inflected and flexible paradigm, we can encourage the growth of new institutional and disciplinary alignments capable of meeting the challenges of a rapidly changing world. 